\title{
Severe generalized recessive dystrophic epidermolysis bullosa
}

INSERM

\section{Source}

INSERM. (1999). Orphanet: an online rare disease and orphan drug data base. Severe generalized recessive dystrophic epidermolysis bullosa. ORPHA:79408

Severe generalized recessive dystrophic epidermolysis bullosa (RDEB-sev gen) is the most severe subtype of dystrophic epidermolysis bullosa (DEB, see this term), formerly known as the Hallopeau-Siemens type, and is characterized by generalized cutaneous and mucosal blistering and scarring associated with severe deformities and major extracutaneous involvement. 